\title{
Organization of the biosynthetic gene cluster for the macrolide antibiotic spiramycin in Streptomyces ambofaciens
}

\author{
Fatma Karray, $†$ Emmanuelle Darbon, Nathalie Oestreicher, \\ Hélène Dominguez,ł Karine Tuphile,§ Josette Gagnat, \\ Marie-Hélène Blondelet-Rouault, Claude Gerbaud and Jean-Luc Pernodet
}

Correspondence

Jean-Luc Pernodet

jean-luc.pernodet@igmors.

u-psud.fr

Received 18 May 2007

Revised 21 August 2007

Accepted 22 August 2007

\author{
CNRS UMR8621, Université Paris-Sud, Institut de Génétique et Microbiologie, Bâtiment 400, \\ F-91405 Orsay Cedex, France
}

\begin{abstract}
Spiramycin, a 16-membered macrolide antibiotic used in human medicine, is produced by Streptomyces ambofaciens; it comprises a polyketide lactone, platenolide, to which three deoxyhexose sugars are attached. In order to characterize the gene cluster governing the biosynthesis of spiramycin, several overlapping cosmids were isolated from an $S$. ambofaciens gene library, by hybridization with various probes (spiramycin resistance or biosynthetic genes, tylosin biosynthetic genes), and the sequences of their inserts were determined. Sequence analysis showed that the spiramycin biosynthetic gene cluster spanned a region of over $85 \mathrm{~kb}$ of contiguous DNA. In addition to the five previously described genes that encode the type I polyketide synthase involved in platenolide biosynthesis, 45 other genes have been identified. It was possible to propose a function for most of the inferred proteins in spiramycin biosynthesis, in its regulation, in resistance to the produced antibiotic or in the provision of extender units for the polyketide synthase. Two of these genes, predicted to be involved in deoxysugar biosynthesis, were inactivated by gene replacement, and the resulting mutants were unable to produce spiramycin, thus confirming their involvement in spiramycin biosynthesis. This work reveals the main features of spiramycin biosynthesis and constitutes a first step towards a detailed molecular analysis of the production of this medically important antibiotic.
\end{abstract}

\section{INTRODUCTION}

Macrolides are a large class of natural products, many of which are effective antibacterial agents. They are mostly produced by actinobacteria belonging to the genera Streptomyces, Saccharopolyspora or Micromonospora. Their structures consist of a macrocyclic lactone to which one or

tPresent address: Centre de Biotechnologie de Sfax, B.P 'K', 3038 Sfax, Tunisia.

łPresent address: Université d'Avignon, IUT, Site Agroparc, BP 1207, F84911 Avignon Cedex 9, France.

§Present address: Unité Bactéries Lactiques et Pathogènes Opportunistes, Bâtiment 222, INRA, F-78352 Jouy en Josas Cedex, France.

Abbreviations: NRPS, non-ribosomal peptide synthetase; PKS, polyketide synthase.

The GenBank/EMBL/DDBJ accession numbers for the sequences of the regions downstream and upstream of the PKS genes are AM709783 and AM709784.

Details of the construction of pWED2 and pOSV238 are available as supplementary material with the online version of this paper. several sugar moieties are attached. The macrolactone is synthesized through the repeated condensation of simple carboxylic acid units catalysed by type I polyketide synthase (PKS). Macrolides bind to the large subunit of the bacterial ribosome, thereby inhibiting protein synthesis, which confers on them their antibacterial activity (Gale et al., 1981; Hansen et al., 2002). They also inhibit ribosome assembly in some bacteria such as Staphylococcus aureus (Champney \& Tober, 2000). Macrolides are an old family of antibacterial agents, as erythromycin was introduced in clinical practice in the 1950 s, but they still play an important role in the chemotherapy of infectious diseases. This is mostly due to the development of semi-synthetic derivatives, for instance clarithromycin, azithromycin and more recently ketolides, with improvements to features such as stability, pharmacokinetics and activity against resistant bacteria (Schönfeld \& Kirst, 2002). The characterization of macrolide biosynthetic gene clusters has opened the way to rational genetic yield improvement of production strains (Stratigopoulos et al., 2004) and to the development of combinatorial strategies for the synthesis of new macrolides (Butler et al., 2002; 
Hutchinson \& McDaniel, 2001; Katz, 1997; Long et al., 2002; Melançon \& Liu, 2007).

Streptomyces ambofaciens produces spiramycin, composed of a 16-membered polyketide lactone ring (platenolide) on which two amino sugars (mycaminose and forosamine) and one neutral sugar (mycarose) are attached. Spiramycin is produced as a mixture of three major compounds differing by acyl substitutions at the position of the hydroxyl group at carbon 3 (Fig. 1). Spiramycin is used in human medicine as an antibacterial agent (Smith, 1988) and also for the treatment of Toxoplasma infections (McCabe \& Oster, 1989). Several genes that confer spiramycin resistance in heterologous hosts have been cloned from S. ambofaciens (Pernodet et al., 1999; Richardson et al., 1987), and spiramycin biosynthetic genes were shown to be located in the vicinity of one of the resistance genes, srmB (Richardson et al., 1990). The five genes encoding the PKS were characterized (Kuhstoss et al., 1996), and the product of another gene, $\operatorname{srmR}$, was shown to be a transcriptional activator (Geistlich et al., 1992). However, only partial sequence data were available, and the complete cluster has not been characterized.

The cloning, sequencing and analysis of the gene cluster for the biosynthesis of spiramycin in S. ambofaciens is reported here. This provides information on its gene organization and on the spiramycin biosynthetic pathway and an indication of the regulation of its expression. This work will facilitate further genetic and biochemical studies of this cluster and also give access to genes that could be helpful for the combinatorial biosynthesis of new macrolide molecules.

\section{METHODS}

Strains, plasmids and culture conditions. Strains and plasmids used in this study are described in Table 1. The construction of some of the vectors used in this work is described in the supplementary material. Standard media and culture conditions were used (Kieser et al., 2000; Sambrook \& Russell, 2001). The following antibiotics were added to the medium when required for selection: ampicillin

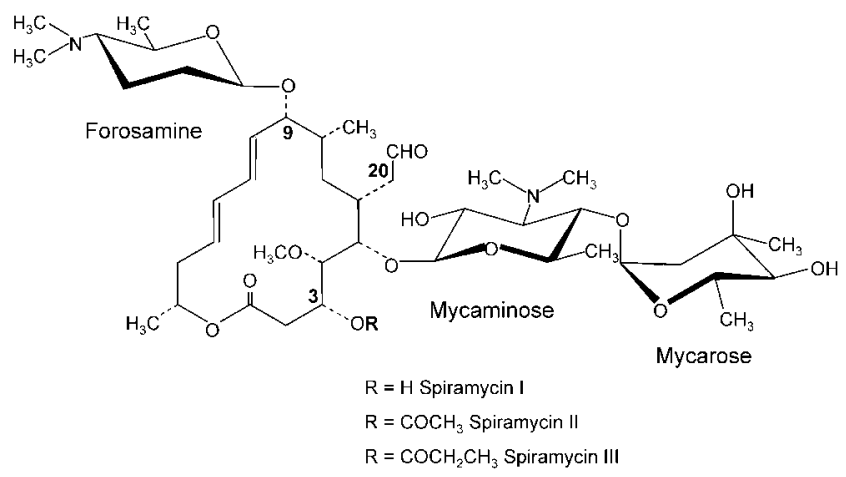

Fig. 1. Structure of spiramycins.
(Amp), apramycin (Apr), hygromycin B (Hyg), puromycin (Pur) and thiostrepton (Tsr). For spiramycin production, S. ambofaciens strains were grown in MP5 liquid medium as described previously (Pernodet et al., 1993). The detection and quantification of spiramycin in culture supernatants was performed by bioassay or HPLC as described previously (Gourmelen et al., 1998).

DNA manipulations. All DNA manipulations, cloning and transformation experiments in Escherichia coli and S. ambofaciens were performed according to standard protocols (Kieser et al., 2000; Sambrook \& Russell, 2001). Radiolabelled DNA probes were prepared with the Megaprime DNA labelling system (GE Healthcare).

Construction and screening of cosmid libraries. Two cosmid libraries of $S$. ambofaciens DNA were constructed, using the cosmid pWED1 for the strain ATCC 23877 library and pWED2 for the strain OSC2 library. OSC2 is a derivative of ATCC 23877. These two S. ambofaciens strains differ only by the presence of pSAM2, which is absent in OSC2; their growth, differentiation and antibiotic production abilities are indistinguishable (Raynal et al., 2006). Total DNA was partially digested with BamHI and fragments of 35 to $45 \mathrm{~kb}$ were ligated with Bam HI-digested cosmid vectors. In vitro packaging was performed with the Packagene Lambda DNA packaging system (Promega), according to the manufacturer's protocol. The phage particles were used to infect the E. coli SURE strain. Colony hybridization was performed on about 2000 clones with various radiolabelled probes. Several hybridizing clones were obtained, the cosmids they contained were characterized by their restriction patterns and some were chosen for sequencing and further studies. The cosmids pOS49.1, pSPM5 and pSMP7 came from the first library, constructed with pWED1. The cosmid pSPM36 came from the second library, constructed with pWED2.

DNA sequencing, sequence analysis and annotation. DNA sequencing of cosmids pSPM5 and pSPM7 was performed by standard shotgun cloning followed by automated DNA sequencing carried out on double-stranded DNA templates to obtain at least sixfold coverage. Sequencing was done by Eurogenetec or Genome Express. Primer walking was used to close the gaps. Fragments from the cosmids pOS49.1 and pSPM36 were sequenced by primer walking. A software program, combining an analysis similar to that performed by Frame plot (Ishikawa \& Hotta, 1999) with an analysis similar to that performed by Glimmer (Salzberg et al., 1998) (C. Gerbaud, unpublished), was used to identify protein-coding regions. Sequence analysis and comparisons were performed using BLAST (Altschul et al., 1997) and CD-Search (Marchler-Bauer \& Bryant, 2004).

Targeted disruption of spiramycin biosynthetic genes. The construction of an orf3 in-frame deletion mutant (strain SPM24) was described previously (Raynal et al., 2006).

An in-frame orf2 deletion mutant was also created by PCR targeting (Chaveroche et al., 2000; Gust et al., 2003; Yu et al., 2000) followed by in vivo excision of the interrupting resistance cassette (Raynal et al., 2006). For this purpose, a $4.5 \mathrm{~kb}$ EcoRI-BamHI fragment containing orf 2 and flanking genes, from srmGI to orf3, was cloned into the plasmid pUC19, yielding pOS49.99. This plasmid was introduced into E. coli strain KS272 already containing pKOBEG (Chaveroche et al., 2000) and expressing the $\lambda$-RED recombination system. The Apr

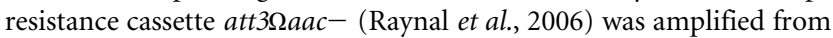
pOSV211 using the primers ORF2A (5'-CCCGCGCGGCAGCCTCTCCGTGATCGAGTCCGGCGTGACCATCGCGCGCGCTTCGTTCGG-3') and ORF2B (5'-GCTCCGTGCGTCATGCAGGAAGGTGTCGTAGTCGCGGTAGATCTGCCTCTTCGTCCCGAA-3') [sequences identical to the beginning (ORF2A) and end (ORF2B) of the orf2 coding sequence are underlined]. The resulting PCR product was used 
Table 1. Bacterial strains and plasmids used in this study

\begin{tabular}{|c|c|c|}
\hline Strain & Description & Source/reference \\
\hline \multicolumn{3}{|l|}{ S. ambofaciens } \\
\hline ATCC 23877 & Wild-type S. ambofaciens strain & ATCC \\
\hline SPM21 & orf $2:: a t t 3 \Omega a a c-$ in OSC2 & This work \\
\hline SPM22 & orf $2::$ att 3 in OSC2 & This work \\
\hline SPM23 & orf $3::$ att $1 \Omega h y g-$ in OSC2 & Raynal et al. (2006) \\
\hline \multicolumn{3}{|l|}{ E. coli } \\
\hline DH5 $\alpha$ & General cloning host strain & Promega \\
\hline KS272/pKOBEG & Used for PCR-targeted mutagenesis & Chaveroche et al. (2000) \\
\hline SURE & Host strain for cosmid libraries & Stratagene \\
\hline S17.1 & Host strain for conjugation from E. coli to $S$. ambofaciens & Simon et al. (1983) \\
\hline \multicolumn{3}{|l|}{ Plasmid } \\
\hline pOSV211 & 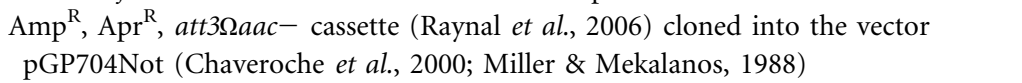 & This work \\
\hline pOSV238 & $\begin{array}{l}\mathrm{Hyg}^{\mathrm{R}} \text {, derivative of } \mathrm{pBK}-\mathrm{CMV} \text { (Stratagene) in which the neo gene has been } \\
\text { replaced by the } \Omega h y g \text { cassette }\end{array}$ & This work \\
\hline pOSV508 & $\begin{array}{l}\mathrm{Amp}^{\mathrm{R}}, \mathrm{Tsr}^{\mathrm{R}}, \text { E. coli-Streptomyces shuttle plasmid expressing the Xis and Int } \\
\text { proteins for site-specific excision of excisable cassettes }\end{array}$ & Raynal et al. (2006) \\
\hline $\begin{array}{l}\text { pOS49.1, pSPM5, } \\
\text { pSPM7 }\end{array}$ & $\begin{array}{l}\text { Cosmids from the S. ambofaciens ATCC } 23877 \text { gene library containing part of the } \\
\text { spiramycin cluster }\end{array}$ & This work \\
\hline pSPM36 & $\begin{array}{l}\text { Cosmid from the S. ambofaciens OSC2 gene library containing part of the } \\
\text { spiramycin cluster }\end{array}$ & This work \\
\hline
\end{tabular}

to transform E. coli strain KS272 containing pKOBEG and pOS49.99. After selection for Apr resistance, clones were obtained in which most of the plasmid-borne orf 2 coding sequence has been replaced by the

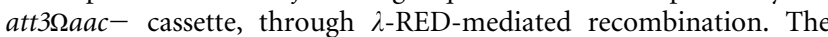
resulting plasmid was named pSPM17. The insert of pSPM17, obtained as a EcoRI/Klenow-XbaI DNA fragment, was cloned in the plasmid pOSV238 $\left(\mathrm{Hyg}^{\mathrm{R}}\right)$, previously digested by BamHI/Klenow$\mathrm{XbaI}$, yielding pSPM21. It was introduced into $S$. ambofaciens OSC2 via protoplast transformation and Apr selection was applied. $\mathrm{Apr}^{\mathrm{R}}$ transformants were screened for sensitivity to Hyg, indicating a double-crossover allelic exchange. This was confirmed by PCR and Southern blot analysis. One orf $2:: a t t 3 \Omega a a c-S$. ambofaciens mutant strain was chosen for further studies and named SPM21. In order to

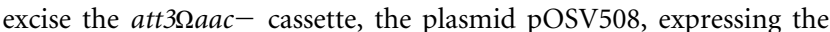
excisionase and the integrase from PSAM2, was introduced into strain SPM21. As a result, the Apr-resistance determinant was excised through site-specific recombination, leading to an in-frame orf2 deletion mutant. After curing of pOSV508, the resulting strain, verified by PCR amplification and sequencing of the PCR products, was named SPM22.
Complementation of SPM22 and SPM24 mutants. The plasmid pOS49.52, a pIJ903 derivative expressing orf3 under the control of the erm $E^{\star}$ promoter, was described previously (Raynal et al., 2006). It was introduced into strain SPM24 by protoplast transformation.

The orf2 coding sequence was amplified with the primers KF8 (5'AAGCTTCCGGGTCGACTGGAACTGAACCCGAGGG-3', HindIII site underlined) and KF11 (5'-GGATCCGATGGTCATGTGAGGCTCCGTGCGTCAT-3', BamHI site underlined). The resulting PCR product was cloned into pUWL201 digested by BamHI and HindIII, yielding PSPM30, in which orf2 is expressed under the control of the ermE $E^{\star}$ promoter. The SPM22 mutant was also complemented by orf1a from Streptomyces fradiae, the producer of tylosin. The primers KF12 (5'-AAGCTTGCGAGGAGCAGCCCGATGGCGGCGAGCA-3', HindIII site underlined) and KF13 (5'-GGATCCCCCTGTCACGGGTGGCTCCTGCCGGCCC-3', BamHI site underlined) were used to amplify orfla from $S$. fradiae total DNA. The resulting PCR product was cloned into pUWL201 digested by BamHI and HindIII to obtain pSPM33. The plasmids pSPM30 and pSPM33 were introduced into strain SPM22 by protoplast transformation. 


\section{RESULTS AND DISCUSSION}

\section{Cloning and sequencing of the spiramycin biosynthetic gene cluster}

Large cloned DNA fragments of the spiramycin biosynthetic gene cluster were isolated by screening $S$. ambofaciens cosmid libraries by colony hybridization with various probes. The first probe (P1; Fig. $2 \mathrm{a})$ corresponded to $t y l \mathrm{~B}$, a gene from the tylosin cluster in $S$. fradiae involved in the biosynthesis of mycaminose (Merson-Davies \& Cundliffe, 1994), a sugar also found in the spiramycin molecule. A tylB orthologue is present in $S$. ambofaciens, as some cosmids from an $S$. ambofaciens library restored tylosin biosynthesis when introduced into a tylosin non-producing mutant affected in tylB (Richardson et al., 1990). From a colony hybridizing with the probe $\mathrm{P} 1$, the cosmid pOS49.1 was extracted. A $3.3 \mathrm{~kb}$ SacI DNA fragment, responsible for the hybridization, was identified, subcloned and sequenced. Sequence analysis showed the presence of four coding sequences (two complete, two partial). One of them encoded a protein showing end-to-end similarity to TylB
(64\% identity). Inactivation of this coding sequence (see below) abolished spiramycin production, confirming that the gene identified was part of the spiramycin cluster.

More sequence data were generated from pOS49.1, revealing that this region was located between two genes sequenced previously, $\operatorname{srm} X$ (orf9c) on one side and $\operatorname{srm} G$ on the other (Geistlich et al., 1992) (Fig. 2b). In order to select other cosmids, the library was probed again with three probes. Two of them were fragments of pOS49.1, each located at one end of the sequenced region (probes P2 and P3; Fig. 2a). The third one (P4; Fig. 2a) contained the srmD gene, a spiramycin-resistance determinant cloned previously (Pernodet et al., 1999; M.-H. Blondelet-Rouault, unpublished) and part of the upstream gene. The products of $\mathrm{srmD}$ and of the upstream gene were similar to those of $m d m A$ and $m d m B$ from Streptomyces mycarofaciens, involved respectively in midecamycin resistance and biosynthesis (Hara \& Hutchinson, 1992). Several cosmids hybridized with these probes, although not with all three of them, and from their restriction maps two cosmids that showed minimal overlap with pOS49.1 were selected. These

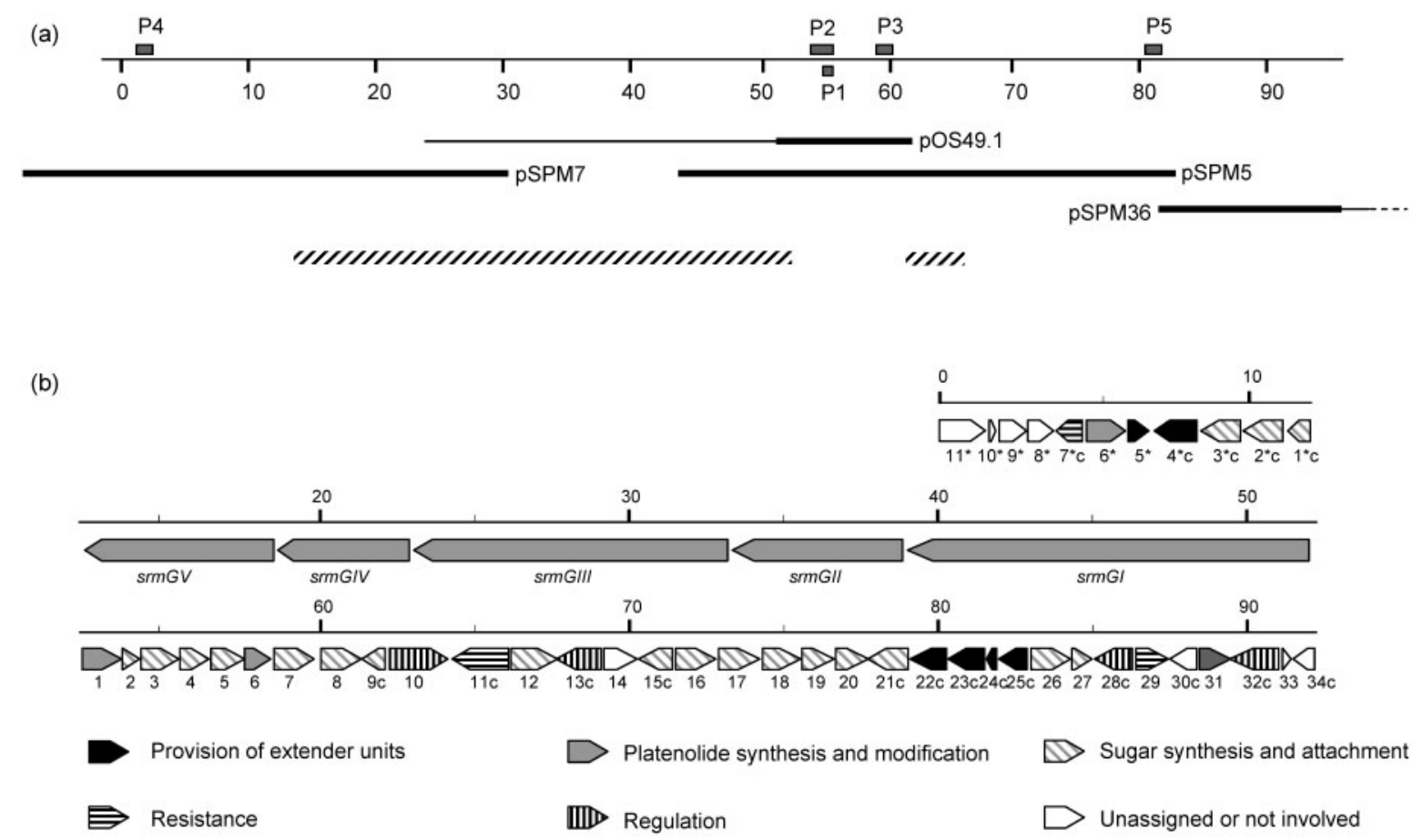

Fig. 2. Spiramycin biosynthetic gene cluster. (a) Schematic representation of a $\sim 90 \mathrm{~kb}$ locus from the $\mathrm{S}$. ambofaciens chromosome. The positions of the fragments hybridizing with the various probes used are indicated (P1 to P5). Probe P1, $1 \mathrm{~kb}$ Nael fragment containing most of the tylB gene from S. fradiae; probe P2, $3.7 \mathrm{~kb}$ BamHI-Pstl fragment containing part of srmGl, orf1, orf2 and part of orf3; probe P3, $2 \mathrm{~kb}$ Pstl-BamHI fragment containing orf7 and orf8; probe P4, $1.8 \mathrm{~kb}$ Pstl-BamHI fragment containing $s r m D\left(\mathrm{orf7}^{*} \mathrm{c}\right.$ ); probe P5, PCR product containing part of orf23c, orf24c and part of orf25c. Lines below correspond to the positions of the inserts of some of the cosmids, thick lines indicating regions of the insert that have been sequenced. Hatched lines indicate the two regions sequenced previously: the PKS genes (Burgett et al., 1999; Kuhstoss et al., 1996) and $\operatorname{srm} X$ (orf9c), srmR (orf10) and srmB (orf11c) (Geistlich et al., 1992). (b) Genetic organization of the spiramycin biosynthetic gene cluster. In the gene names, ' $c$ ' indicates those orientated to the left. The proposed functions of the gene products in spiramycin biosynthesis are indicated by various filling patterns. 
were designated pSPM5 and pSPM7 (Fig. 2a). Sequence analysis showed that the right end of the pSPM5 insert could still be located within the spiramycin cluster. Therefore, another hybridization experiment was performed using probe P5, corresponding to the right end of the pSPM5 insert (Fig. 2a). One cosmid, named pSPM36, overlapping pSPM5 and spanning the remainder of the spiramycin cluster, was partially sequenced (Fig. 2a).

From the analysis of these sequences and their alignment with the sequences of the five PKS genes (Burgett et al., 1999), it was possible to deduce the gene organization of the region. The five $s r m G$ genes, encoding the PKS, occupy about $40 \mathrm{~kb}$. Upstream of srmGI, 34 ORFs (orf1 to orf34c) account for about $40 \mathrm{~kb}$, and downstream of srmGV, 11 ORFs $\left(\right.$ orf $11^{*} c$ to orf $11^{*}$ ) occupy about $12 \mathrm{~kb}$. The inferred products of these ORFs were compared to protein databases. From these comparisons, most of the deduced protein products could be assigned putative functions in spiramycin biosynthesis (Fig. 2; Table 2).

\section{Genes involved in the provision of extender units for the PKS, in platenolide biosynthesis and modification}

The five megagenes, srmGI to srmGV, encoding the PKS have been sequenced and studied previously (Burgett et al., 1999; Kuhstoss et al., 1996). The organization of the modules within the five SrmG proteins is the same as in other known PKS involved in the biosynthesis of 16-membered macrolides, and the domain organization is similar to that of the tylosin or niddamycin PKS (McDaniel et al., 2005). However, the extender units used for platenolide biosynthesis are different from those used for tylactone biosynthesis. The platenolide PKS was predicted to incorporate seven extender units: four malonyl-CoA, one ethylmalonyl-CoA, one methylmalonyl-CoA and one unknown product, incorporated by module 6 (Kuhstoss et al., 1996).

The product of $\operatorname{orf} 4^{*} c$, a crotonyl-CoA reductase, presumably contributes to the flux of ethylmalonyl-CoA. Crotonyl-CoA reductase genes are found in other polyketide biosynthetic clusters where the PKS uses ethylmalonyl extender units, such as the tylosin or concanamycin clusters (Cundliffe et al., 2001; Haydock et al., 2005).

Five proteins, the products of orf $55^{\star}$, orf $22 c$, orf $23 c$, orf $24 c$ and orf $25 c$, are similar to FkbG, FkbH, FkbI, FkbJ and FkbK, respectively, proteins that are involved in the biosynthesis of methoxymalonyl-acyl carrier protein (ACP) in Streptomyces hygroscopicus var. ascomyceticus, the producer of the macrolide FK520 (ascomycin) (Wu et al., 2000). The greatest similarities are observed with proteins encoded in the geldanamycin and concanamycin clusters (Haydock et al., 2005; Rascher et al., 2003). Recently, sequence comparison of various acyltransferase domains incorporating methoxymalonate allowed identification of a sequence motif predicting the incorporation of this extender unit (Haydock et al., 2005). The conservation of this motif in the AT domain of module 6 in SrmGIV, together with the presence of the five genes involved in methoxymalonyl-ACP biosynthesis, strongly support the incorporation of methoxymalonate by module 6 .

Several other gene products are predicted to be involved in lactone ring biosynthesis or modification. A type II thioesterase is encoded by orf6. Such enzymes play an editing role in the biosynthesis of polyketides (Butler et al., 1999; Heathcote et al., 2001). The product of orf1 is a cytochrome $\mathrm{P}_{450}$ hydroxylase, probably involved in ring hydroxylation at position C20 (Fig. 1). The deduced acyltransferase encoded by orf $\sigma^{*}$ is similar to acyltransferases involved in lactone ring acylation. Therefore, Orf6* might be involved in ring acylation at position 3 , leading to the biosynthesis of spiramycins II and III.

Another important ring modification during the early steps of spiramycin biosynthesis is that at position 9. The PKS generates platenolide I, with a keto group at position 9 (Omura et al., 1979), which is later converted to platenolide II, with a hydroxyl group at $\mathrm{C} 9$, by a postPKS ketoreductase. Indeed, the presence of such an activity in $S$. ambofaciens is attested by the fact that the keto group at $\mathrm{C} 9$ in tylactone could be modified and that forosamine could then be attached at this position by enzymes from $S$. ambofaciens (Omura et al., 1983). Such post-PKS reductases have been described previously, for instance AveF from Streptomyces avermitilis (Ikeda et al., 1999), but none of the spiramycin cluster deduced proteins presented similarity to characterized post-PKS ketoreductases. Nonetheless, the product of orf 31 shows similarity to oxidoreductases (COG0667, pfam00248) and could be a candidate to perform this reaction.

No gene encoding the phosphopantetheinyl transferase required for the post-translational modification of the PKS is present in the spiramycin cluster. A phosphopantetheinyl transferase is encoded by alpN in the alp cluster, located in the terminal inverted repeats of the $S$. ambofaciens chromosome (Pang et al., 2004), but it is not known whether this enzyme is the one involved in the spiramycin PKS modification.

\section{Genes for deoxysugar biosynthesis}

The three deoxysugars present in the structure of spiramycin are also found in other macrolide molecules whose biosyntheses have been thoroughly studied. Mycaminose is found in tylosin, produced by S. fradiae; the genes involved in its biosynthesis have been identified and a biosynthetic pathway has been established (Cundliffe et al., 2001; Melançon et al., 2005). Mycarose is found in erythromycin and tylosin and its biosynthetic genes were first characterized in Saccharopolyspora erythraea (Gaisser et al., 1997, 1998; Summers et al., 1997) and S. fradiae (Bate et al., 2000; Takahashi et al., 2005). Forosamine biosynthetic genes were studied in Saccharopolyspora spinosa, the spinosyn producer (Waldron et al., 2001; Zhao et al., 
Table 2. Components of the spiramycin biosynthetic gene cluster

Abbreviations: For, forosamine; Mcn, mycaminose; Mcr, mycarose. Percentages of identity/similarity refer to deduced amino acid sequence comparisons.

\begin{tabular}{|c|c|c|c|c|c|c|}
\hline \multirow[t]{2}{*}{ ORF } & \multirow{2}{*}{$\begin{array}{l}\text { Product } \\
\text { size }(\text { aa })\end{array}$} & \multicolumn{3}{|c|}{ Best BLAST hit } & \multirow[t]{2}{*}{ Putative function } & \multirow{2}{*}{$\begin{array}{c}\text { Proposed role in } \\
\text { spiramycin biosynthesis }\end{array}$} \\
\hline & & $\begin{array}{l}\text { Accession no. or } \\
\text { reference }\end{array}$ & Species & $\begin{array}{c}\text { Identity/ } \\
\text { similarity (\%) }\end{array}$ & & \\
\hline $\operatorname{orf} 11^{*}$ & Partial & CAA67249 & $\begin{array}{l}\text { Streptomyces } \\
\text { pristinaespiralis }\end{array}$ & $49 / 61$ & $\begin{array}{l}\text { Non-ribosomal peptide } \\
\text { synthetase }\end{array}$ & Not involved \\
\hline $\operatorname{orf} 10^{*}$ & 75 & CAB38589 & $\begin{array}{l}\text { Streptomyces coelicolor } \\
\text { A3(2) }\end{array}$ & $69 / 89$ & MbtH-like protein & Not involved \\
\hline orf $9^{*}$ & 293 & CAC22118 & Streptomyces griseus & $62 / 72$ & $\begin{array}{l}\text { ABC transporter } \\
\text { ATP-binding protein }\end{array}$ & Not involved \\
\hline $\operatorname{orf} 8^{*}$ & 276 & AAX31554 & Streptomyces filamentosus & $63 / 77$ & $\begin{array}{l}\mathrm{ABC} \text { transporter } \\
\text { transmembrane protein }\end{array}$ & Not involved \\
\hline $\operatorname{orf} 7^{*} c$ & 282 & CAA66307 & Streptomyces fradiae & $56 / 72$ & rRNA methyltransferase & Resistance \\
\hline orf6 $6^{*}$ & 414 & AAA26781 & Streptomyces mycarofaciens & $76 / 85$ & Acyltransferase & Lactone ring modification \\
\hline orf $5^{*}$ & 223 & AAA26782 & Streptomyces mycarofaciens & $85 / 93$ & O-Methyltransferase & $\begin{array}{l}\text { Provision of extender units } \\
\text { for PKS }\end{array}$ \\
\hline $\operatorname{orf} 4^{*} \mathrm{c}$ & 449 & ABG67707 & Streptomyces mycarofaciens & $87 / 92$ & Crotonyl-CoA reductase & $\begin{array}{l}\text { Provision of extender units } \\
\text { for PKS }\end{array}$ \\
\hline $\operatorname{orf} 3^{*} c$ & 421 & ABG67706 & Streptomyces mycarofaciens & $90 / 95$ & Glycosyltransferase & Sugar attachment \\
\hline orf $2^{*} \mathrm{C}$ & 423 & ABG67705 & Streptomyces mycarofaciens & $61 / 66$ & $\begin{array}{l}\text { Glycosyltransferase auxiliary } \\
\text { protein }\end{array}$ & Sugar attachment \\
\hline $\operatorname{orfl} 1^{*} \mathrm{C}$ & 236 & ABG67704 & Streptomyces mycarofaciens & $82 / 88$ & $\begin{array}{l}\text { NDP-aminohexose } \\
N \text {-dimethyltransferase }\end{array}$ & $\begin{array}{l}\text { Sugar biosynthesis } \\
\text { (Mcn or For) }\end{array}$ \\
\hline$s r m G V$ & 1891 & $\begin{array}{l}\text { Burgett et al. } \\
\text { (1999) }\end{array}$ & & & Type I PKS & Platenolide biosynthesis \\
\hline srmGIV & 1596 & $\begin{array}{l}\text { Burgett et al. } \\
\text { (1999) }\end{array}$ & & & Type I PKS & Platenolide biosynthesis \\
\hline srmGIII & 3724 & $\begin{array}{l}\text { Burgett et al. } \\
\text { (1999) }\end{array}$ & & & Type I PKS & Platenolide biosynthesis \\
\hline srmGII & 2008 & $\begin{array}{l}\text { Burgett et al. } \\
\text { (1999) }\end{array}$ & & & Type I PKS & Platenolide biosynthesis \\
\hline srmGI & 4552 & $\begin{array}{l}\text { Burgett et al. } \\
\text { (1999) }\end{array}$ & & & Type I PKS & Platenolide biosynthesis \\
\hline orf1 & 403 & ABG67708 & Streptomyces mycarofaciens & $80 / 88$ & Cytochrome $\mathrm{P}_{450}$ hydroxylase & Lactone ring modification \\
\hline orf 2 & 116 & $\begin{array}{l}\text { Melançon et al. } \\
(2007) \dagger\end{array}$ & Streptomyces fradiae & $58 / 71$ & NDP-hexose isomerase & Sugar biosynthesis (Mcn) \\
\hline orf 3 & 388 & ABG67699 & Streptomyces mycarofaciens & $79 / 85$ & $\begin{array}{l}\text { NDP-hexose } \\
\text { aminotransferase }\end{array}$ & Sugar biosynthesis (Mcn) \\
\hline orf4 & 302 & ABG67700 & Streptomyces mycarofaciens & $83 / 89$ & NDP-glucose synthase & Sugar biosynthesis \\
\hline orf5 & 345 & ABG67702 & Streptomyces mycarofaciens & $84 / 88$ & NDP-glucose dehydratase & Sugar biosynthesis \\
\hline orf6 & 267 & ABG67701 & Streptomyces mycarofaciens & $69 / 78$ & Type II thioesterase & PKS editing \\
\hline orf7 & 469 & ABG67703 & Streptomyces mycarofaciens & $72 / 78$ & NDP-hexose dehydratase & $\begin{array}{l}\text { Sugar biosynthesis } \\
\text { (Mcr and For) }\end{array}$ \\
\hline orf 8 & 382 & AAG23279 & Saccharopolyspora spinosa & $61 / 74$ & $\begin{array}{l}\text { NDP-hexose } \\
\text { aminotransferase }\end{array}$ & Sugar biosynthesis (For) \\
\hline $\begin{array}{l}\text { orf9c } \\
\quad=\operatorname{srmX}\end{array}$ & 239 & CAA45052 & SrmX (S. ambofaciens) & & $\begin{array}{l}\text { NDP-aminohexose } \\
\mathrm{N} \text {-dimethyltransferase }\end{array}$ & $\begin{array}{l}\text { Sugar biosynthesis } \\
\text { (Mcn or For) }\end{array}$ \\
\hline $\begin{array}{l}\text { orf10 } \\
\quad=\text { srmR }\end{array}$ & 655 & CAA45051 & SrmR (S. ambofaciens) & & Regulatory protein & Regulatory protein \\
\hline $\begin{array}{l}\text { orf } 11 c \\
\quad=\operatorname{srmB}\end{array}$ & 550 & CAA45050 & SrmB (S. ambofaciens) & & $\begin{array}{l}\text { ABC transporter } \\
\text { ATP-binding protein }\end{array}$ & Resistance \\
\hline orf12 & 433 & AAF72550 & Streptomyces fradiae & $71 / 83$ & NDP-hexose dehydratase & Sugar biosynthesis (For) \\
\hline orf13c & 481 & CAA18333 & $\begin{array}{l}\text { Streptomyces coelicolor } \\
\text { A3(2) }\end{array}$ & $75 / 86$ & GTPase & $\begin{array}{l}\text { Putatively involved in } \\
\text { regulation }\end{array}$ \\
\hline orf14 & 347 & EAR69813 & Bacillus cereus & $37 / 54$ & NDP-sugar epimerase & \\
\hline
\end{tabular}


Table 2. cont.

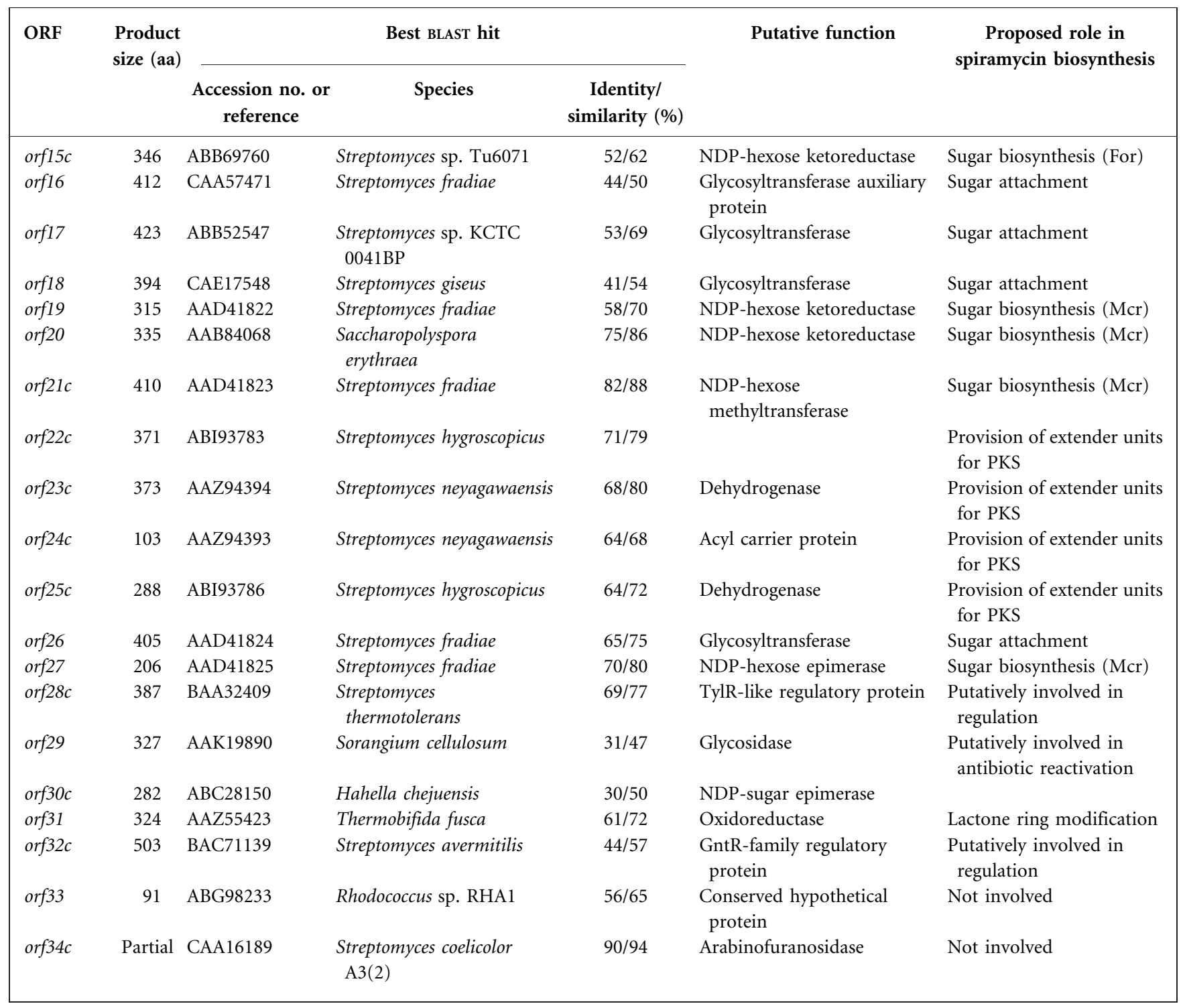

$\dagger$ This match was obtained with TBLASTN, as the product of orf1a from S. fradiae is not in protein databases.

2005). Sequence comparisons, particularly with proteins from S. fradiae, Saccharopolyspora erythraea and Saccharopolyspora spinosa, whose function in mycaminose, mycarose and forosamine biosynthesis is well characterized, enabled us to identify a potential enzyme for each of the steps of the proposed pathways (Fig. 3).

The products of orf14 and orf $30 \mathrm{c}$ are both related to NDPsugar epimerases. However, with the proposed biosynthetic routes, no role could be found for these two proteins in the biosynthesis of spiramycin deoxysugars.

\section{Genes for sugar attachment}

Four genes, $\operatorname{orf}^{*} c$, orf17, orf18 and orf 26 , encode putative glycosyltransferases that could be involved in the attachment of sugars. It was surprising to find four glycosyltransferase genes, as only three sugars are present in the spiramycin molecule. Several hypotheses can be proposed. Firstly, one of these genes might not be expressed or its product could be inactive, but the alignment of the four putative glycosyltransferases with functional glycosyltransferases did not reveal obvious differences suggesting that one of them could be inactive. Secondly, two different glycosyltransferases could perform the same reaction independently, but, to our knowledge, no such case has been described previously. Thirdly, one of the glycosyltransferases could be involved in macrolide inactivation by glycosylation and play a role in resistance towards the produced antibiotic (see below). Sequence comparisons with characterized enzymes that transfer mycaminose, mycarose or forosamine, and analyses 


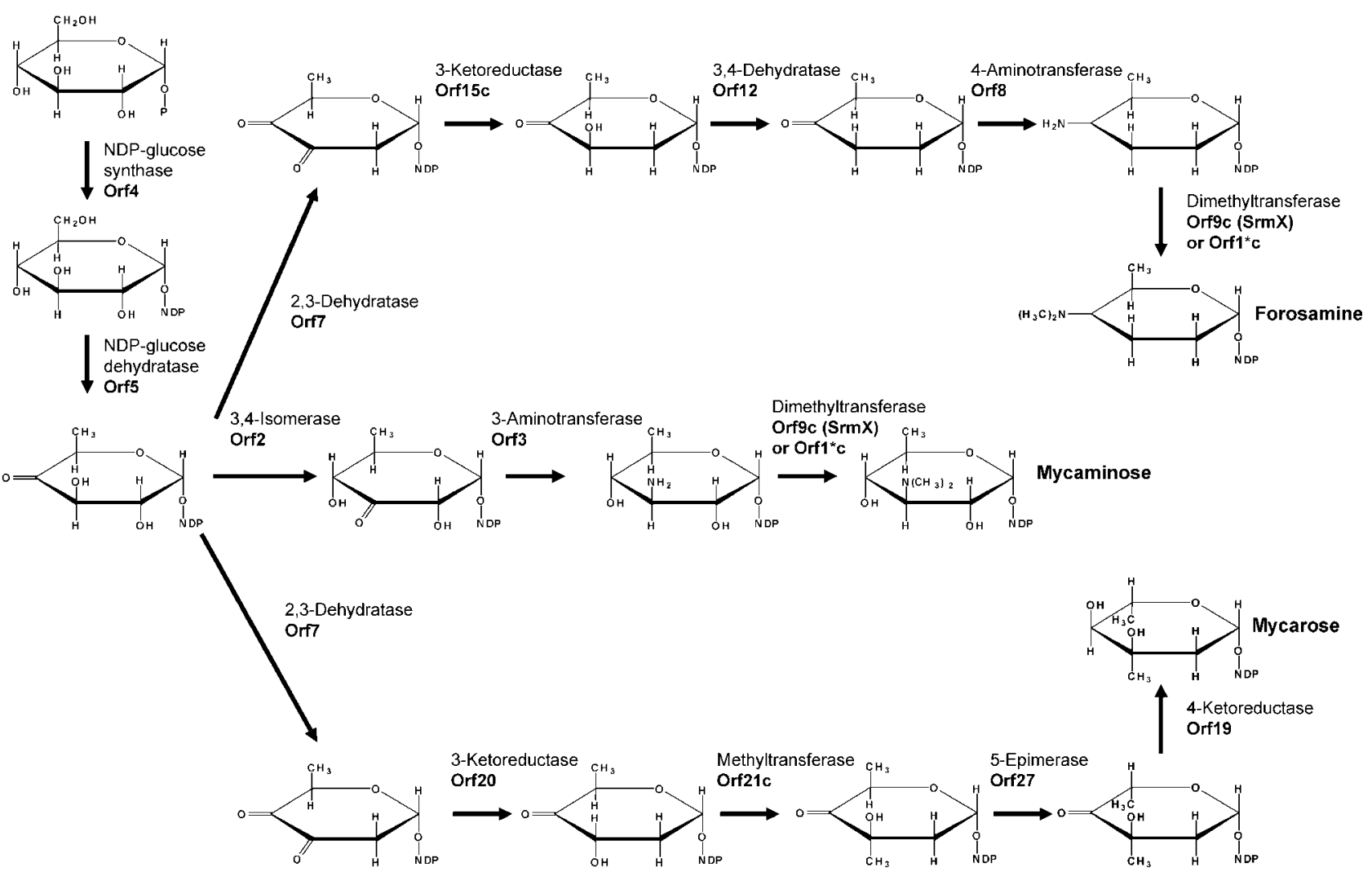

Fig. 3. Proposed pathways and proteins involved in the biosynthesis of the three spiramycin deoxysugars from glucose 1phosphate.

performed with SEARCHGTr, a program for analysis of glycosyltransferases involved in glycosylation of secondary metabolites (Kamra et al., 2005), did not allow us to make unambiguous predictions concerning the sugars transferred by these four putative glycosyltransferases. In addition, two genes, orf $2^{*} \mathrm{C}$ and orf16, encode products that belong to the recently identified family of glycosyltransferase accessory proteins, required for efficient glycosylation (Borisova et al., 2004; Hong et al., 2007; Melançon et al., 2004). These two genes are located immediately upstream of glycosyltransferase genes, as is generally the case. Their products share $42 \%$ amino acid sequence identity. The presence of two glycosyltransferase/ auxiliary protein pairs suggests that each auxiliary protein is preferentially associated with a glycosyltransferase, as shown by Hong et al. (2007).

\section{Resistance genes}

srmB (orf11c) was previously isolated from S. ambofaciens as a spiramycin-resistance determinant (Richardson et al., 1987); it encodes the ATP-binding component of an ABC transporter and is thought to be involved in spiramycin efflux (Schoner et al., 1992). orf $7^{\star}$ was previously isolated from S. ambofaciens as a spiramycin-resistance determinant called srmD (Pernodet et al., 1999); it encodes a methyltransferase modifying 23S rRNA (M.-H. BlondeletRouault; unpublished data).

Inactivation of macrolides by glycosylation has been observed in S. ambofaciens extracts. Two distinct glycosyltransferase activities could be identified from their antibiotic substrate profiles. The gene $\operatorname{gim} A$, encoding the glycosyltransferase responsible for one of these activities, has been detected, and is not located within the spiramycin biosynthetic cluster (Gourmelen et al., 1998). However, the gene responsible for the second activity has not yet been identified. One of the four glycosyltransferases might be responsible for this activity. Macrolide inactivation by glycosyltransferases in macrolide-producing strains has been well studied in Streptomyces antibioticus, the oleandomycin producer. It was demonstrated that intracellular glycosylation inactivates oleandomycin, which is subsequently reactivated, after secretion, by an extracellular glycosidase. Two glycosyltransferases, OleI and OleD, show oleandomycin-glycosylating activity but differ in the pattern of substrate specificity, OleI being much more specific for oleandomycin. A glycosidase OleR converts glycosylated oleandomycin into active oleandomycin (Quiros et al., 1998). The genes oleR and oleI are located in the oleandomycin cluster, while oleD is located elsewhere 
in the genome. As a similar resistance mechanism might operate in S. ambofaciens, we searched for an oleR orthologue, but none was found in the cluster. However, the deduced product of orf 29 had a putative glycosylhydrolase domain (pfam02156). Furthermore, analysis of the Orf29 sequence by SignalP (Nielsen et al., 1997) showed that this protein, having a predicted signal sequence of 30 amino acids, was probably excreted. It might therefore be involved in the reactivation of glycosylated spiramycin.

The two genes orf $9^{\star}$ and orf $8^{\star}$ encode an $\mathrm{ABC}$ transporter. To test their possible involvement in spiramycin resistance, these two genes were expressed in the spiramycin-sensitive host Streptomyces lividans OS456 (Pernodet et al., 1996), but no resistant phenotype was observed (data not shown). Therefore, these genes are probably not involved in spiramycin resistance and might belong to the uncharacterized non-ribosomal peptide synthetase (NRPS) cluster flanking the spiramycin cluster.

\section{Regulatory genes}

The gene $\operatorname{srm} R$ (orf10) has been shown previously to encode a transcriptional activator; its inactivation abolished spiramycin production (Geistlich et al., 1992). Besides $s r m R$, three putative regulatory genes are present: orf $13 c$, orf $28 c$ and orf $32 c$. The deduced product of orf $13 c$ is a putative GTPase belonging to the HflX family. The cellular functions of proteins from this family remain elusive (Brown, 2005). $t y l V$, an orthologue of orf13c, is present in the tylosin cluster, where it might play a regulatory role in tylosin biosynthesis (Stratigopoulos et al., 2004). The deduced product of orf $28 \mathrm{c}$ showed high similarity to AcyB2, an activator of carbomycin biosynthesis from Streptomyces thermotolerans (Arisawa et al., 1993), and to TylR, a pathway-specific transcriptional activator of tylosin biosynthesis in S. fradiae (Bate et al., 1999; Stratigopoulos et al., 2004). The gene orf32c encodes a putative transcriptional regulator from the GntR family. It should be noted that neither SrmR nor any of the putative regulators belong to those families of regulatory proteins that are commonly involved in the regulation of secondary metabolism, such as SARP, LAL or $\gamma$-butyrolactonebinding proteins (Bibb, 2005).

\section{Limits of the cluster and genes of unknown function}

On one side, the resistance gene $s r m D$ probably marks the limit of the spiramycin cluster, as the genes orf $8^{\star}$ and $\operatorname{orf}^{*}$ are not involved in spiramycin resistance and as the other genes orf $10^{*}$ and orf $11^{*}$ encode an $\mathrm{MbtH}$-like protein and an NRPS, respectively, two proteins for which no role in spiramycin biosynthesis could be proposed. The presence of these last two genes suggests that another secondary metabolite biosynthetic gene cluster, involving an NRPS, is adjacent to the spiramycin cluster. The most likely functions for most of the genes from $\operatorname{orf}^{*} c$ to $\operatorname{orf} 28 c$ are either antibiotic biosynthesis or resistance or regulation of secondary metabolism. After orf $28 c$, the limit is not easily predictable; orf 29 might be involved in the reactivation of glycosylated spiramycin, no role could be proposed for orf $30 c$, orf 31 could encode a post-PKS reductase and orf $32 c$ a transcriptional regulator. The two genes orf 33 and orf $34 c$ are probably not part of the spiramycin cluster.

\section{Inactivation of orf3 and orf2}

The gene orf3 encodes an NDP-hexose aminotransferase probably involved in mycaminose biosynthesis. The inactivation of orf 3 was performed early in the course of this study, to verify that the first genes isolated were indeed part of the spiramycin cluster. Inactivation of this gene by inframe deletion using an excisable cassette resulted in a spiramycin non-producing mutant (strain SPM24); spiramycin production could be restored by expression of the cloned orf3 gene in this mutant, as reported previously (Raynal et al., 2006). Spiramycin biosynthesis could also be restored by expressing the $t y l B$ gene from $S$. fradiae in strain SPM24 (data not shown). As TylB is the NDP-hexose aminotransferase involved in mycaminose biosynthesis, this complementation experiment thus supports the involvement of Orf3 in mycaminose rather than in forosamine biosynthesis. Moreover, strain SPM24 was shown to produce platenolide aglycone, as expected if Orf3 is involved in mycaminose biosynthesis (data not shown).

The gene orf 2 encodes an NDP-hexose isomerase and is highly similar to orf1a from $S$. fradiae, whose role in mycaminose biosynthesis was demonstrated recently (Melançon et al., 2005, 2007). This gene was inactivated by in-frame deletion using an excisable cassette and the resulting mutant (orf2::att3) was named SPM22. This mutant was unable to synthesize spiramycin, but production was restored by expression of orf 2 (under the control of the $\mathrm{ermE}^{\star}$ promoter; plasmid pSPM30) or by expression of orfla from $S$. fradiae (under the control of the ermE ${ }^{*}$ promoter; plasmid pSPM33) (data not shown). It is interesting to note that the product of orf2 is also similar ( $46 \%$ identity, $59 \%$ similarity) to that of SAMR0473, a gene clustered with other deoxyhexose biosynthetic genes, and with large type I PKS genes, in the right arm of the $S$. ambofaciens chromosome (Choulet et al., 2006). Nothing is known about the expression of this other PKS I cluster and the product synthesized, but SAMR0473 obviously could not complement orf2 deletion.

\section{Concluding remarks}

The analysis of the spiramycin biosynthetic gene cluster from S. ambofaciens ATCC 23877 provides information on the origin of the precursors used by the PKS, the biosynthetic route for the deoxysugars and putative regulatory genes. For many of the biosynthetic genes, the closest orthologues are found in the midecamycin and tylosin clusters, in agreement with the chemical similarities 
of the macrolide molecules synthesized. Despite this high similarity at the protein level, the gene organization in the spiramycin cluster is strictly identical to that of the tylosin cluster only for the PKS genes and the seven genes upstream (orf1 to orf7 in the spiramycin cluster). From the partial data available on the midecamycin cluster (Cong \& Piepersberg, 2007), the gene organization seems to be conserved between the spiramycin and midecamycin clusters for the seven genes downstream of the PKS and for the seven genes upstream (with the exception of an inversion that affects two genes). The complex regulation of tylosin biosynthesis has been studied thoroughly in S. fradiae (Bignell et al., 2007; and references therein), but the similarity with $S$. ambofaciens is probably limited, as only $t y l R$, one of the multiple genes controlling tylosin biosynthesis, has an orthologue (orf10) in the spiramycin cluster. In addition to the question of regulation, this work also raised questions about the genes whose products are involved in the attachment of deoxysugars and about the existence of a mechanism for inactivation/reactivation of the produced antibiotic. The present determination of the sequence and organization of the spiramycin gene cluster will allow such questions to be addressed via targeted mutations.

\section{ACKNOWLEDGEMENTS}

The authors would like to thank E. Cundliffe for the kind gift of the cloned $t y l B$ gene and of the $S$. fradiae strain, A. Jimenez for the kind gift of the cloned pac gene, M. Guérineau for support and suggestions and S. Lautru for advice and critical reading of the manuscript. F. K. was supported by a CNRS-BDI fellowship. This work was supported in part by the European Union (CT95-0198 and CT-2004-0005224), by Sanofi-Aventis and by the 'ACI Microbiologie 2003' programme (funded by MENESR).

\section{REFERENCES}

Altschul, S. F., Madden, T. L., Schaffer, A. A., Zhang, J., Zhang, Z., Miller, W. \& Lipman, D. J. (1997). Gapped BLAST and PSI-BLAST: a new generation of protein database search programs. Nucleic Acids Res 25, 3389-3402.

Arisawa, A., Kawamura, N., Tsunekawa, H., Okamura, K., Tone, H. \& Okamoto, R. (1993). Cloning and nucleotide sequences of two genes involved in the 4 "-O-acylation of macrolide antibiotics from Streptomyces thermotolerans. Biosci Biotechnol Biochem 57, 2020-2025.

Bate, N., Butler, A. R., Gandecha, A. R. \& Cundliffe, E. (1999). Multiple regulatory genes in the tylosin biosynthetic cluster of Streptomyces fradiae. Chem Biol 6, 617-624.

Bate, N., Butler, A. R., Smith, I. P. \& Cundliffe, E. (2000). The mycarose-biosynthetic genes of Streptomyces fradiae, producer of tylosin. Microbiology 146, 139-146.

Bibb, M. J. (2005). Regulation of secondary metabolism in streptomycetes. Curr Opin Microbiol 8, 208-215.

Bignell, D. R., Bate, N. \& Cundliffe, E. (2007). Regulation of tylosin production: role of a TylP-interactive ligand. Mol Microbiol 63, 838-847.

Borisova, S. A., Zhao, L., Melançon, C. E., III, Kao, C. L. \& Liu, H. W. (2004). Characterization of the glycosyltransferase activity of DesVII: analysis of and implications for the biosynthesis of macrolide antibiotics. J Am Chem Soc 126, 6534-6535.
Brown, E. D. (2005). Conserved P-loop GTPases of unknown function in bacteria: an emerging and vital ensemble in bacterial physiology. Biochem Cell Biol 83, 738-746.

Burgett, S. G., Kuhstoss, S. A., Rao, R. N., Richardson, M. A. \& Rosteck, P. R., Jr (1999). Platenolide synthase gene. United States Patent 5,945,320.

Butler, A. R., Bate, N. \& Cundliffe, E. (1999). Impact of thioesterase activity on tylosin biosynthesis in Streptomyces fradiae. Chem Biol 6, 287-292.

Butler, A. R., Bate, N., Kiehl, D. E., Kirst, H. A. \& Cundliffe, E. (2002). Genetic engineering of aminodeoxyhexose biosynthesis in Streptomyces fradiae. Nat Biotechnol 20, 713-716.

Champney, W. S. \& Tober, C. L. (2000). Specific inhibition of 50 S ribosomal subunit formation in Staphylococcus aureus cells by 16membered macrolide, lincosamide, and streptogramin B antibiotics. Curr Microbiol 41, 126-135.

Chaveroche, M. K., Ghigo, J. M. \& d'Enfert, C. (2000). A rapid method for efficient gene replacement in the filamentous fungus Aspergillus nidulans. Nucleic Acids Res 28, E97.

Choulet, F., Aigle, B., Gallois, A., Mangenot, S., Gerbaud, C., Truong, C., Francou, F.-X., Fourrier, C., Guérineau, M. \& other authors (2006). Evolution of the terminal regions of the Streptomyces linear chromosome. Mol Biol Evol 23, 2361-2369.

Cong, L. \& Piepersberg, W. (2007). Cloning and characterization of genes encoded in dTDP-D-mycaminose biosynthetic pathway from a midecamycin-producing strain, Streptomyces mycarofaciens. Acta Biochim Biophys Sin (Shanghai) 39, 187-193.

Cundliffe, E., Bate, N., Butler, A., Fish, S., Gandecha, A. \& MersonDavies, L. (2001). The tylosin-biosynthetic genes of Streptomyces fradiae. Antonie van Leeuwenhoek 79, 229-234.

Doumith, M., Weingarten, P., Wehmeier, U. F., Salah-Bey, K., Benhamou, B., Capdevila, C., Michel, J. M., Piepersberg, W. \& Raynal, M. C. (2000). Analysis of genes involved in 6-deoxyhexose biosynthesis and transfer in Saccharopolyspora erythraea. Mol Gen Genet 264, 477-485.

Gaisser, S., Bohm, G. A., Cortes, J. \& Leadlay, P. F. (1997). Analysis of seven genes from the eryAI-eryK region of the erythromycin biosynthetic gene cluster in Saccharopolyspora erythraea. Mol Gen Genet 256, 239-251.

Gaisser, S., Bohm, G. A., Doumith, M., Raynal, M. C., Dhillon, N., Cortes, J. \& Leadlay, P. F. (1998). Analysis of eryBI, eryBIII and eryBVII from the erythromycin biosynthetic gene cluster in Saccharopolyspora erythraea. Mol Gen Genet 258, 78-88.

Gale, E. F., Cundliffe, E., Reynolds, P. E., Richmond, M. H. \& Waring, J. M. (1981). The Molecular Basis of Antibiotic Action. New York: Wiley.

Geistlich, M., Losick, R., Turner, J. R. \& Rao, R. N. (1992). Characterization of a novel regulatory gene governing the expression of a polyketide synthase gene in Streptomyces ambofaciens. Mol Microbiol 6, 2019-2029.

Gourmelen, A., Blondelet-Rouault, M.-H. \& Pernodet, J.-L. (1998). Characterization of a glycosyl transferase inactivating macrolides, encoded by gimA from Streptomyces ambofaciens. Antimicrob Agents Chemother 42, 2612-2619.

Gust, B., Challis, G. L., Fowler, K., Kieser, T. \& Chater, K. F. (2003). PCR-targeted Streptomyces gene replacement identifies a protein domain needed for biosynthesis of the sesquiterpene soil odor geosmin. Proc Natl Acad Sci U S A 100, 1541-1546.

Hansen, J. L., Ippolito, J. A., Ban, N., Nissen, P., Moore, P. B. \& Steitz, T. A. (2002). The structures of four macrolide antibiotics bound to the large ribosomal subunit. Mol Cell 10, 117-128. 
Hara, O. \& Hutchinson, C. R. (1992). A macrolide 3-O-acyltransferase gene from the midecamycin-producing species Streptomyces mycarofaciens. J Bacteriol 174, 5141-5144.

Haydock, S. F., Appleyard, A. N., Mironenko, T., Lester, J., Scott, N. \& Leadlay, P. F. (2005). Organization of the biosynthetic gene cluster for the macrolide concanamycin A in Streptomyces neyagawaensis ATCC 27449. Microbiology 151, 3161-3169.

Heathcote, M. L., Staunton, J. \& Leadlay, P. F. (2001). Role of type II thioesterases: evidence for removal of short acyl chains produced by aberrant decarboxylation of chain extender units. Chem Biol 8, 207-220.

Hong, J. S., Park, S. J., Parajuli, N., Park, S. R., Koh, H. S., Jung, W. S., Choi, C. Y. \& Yoon, Y. J. (2007). Functional analysis of DesVIII homologues involved in glycosylation of macrolide antibiotics by interspecies complementation. Gene 386, 123-130.

Hutchinson, C. R. \& McDaniel, R. (2001). Combinatorial biosynthesis in microorganisms as a route to new antimicrobial, antitumor and neuroregenerative drugs. Curr Opin Investig Drugs 2, 1681-1690.

Ikeda, H., Nonomiya, T., Usami, M., Ohta, T. \& Omura, S. (1999). Organization of the biosynthetic gene cluster for the polyketide anthelmintic macrolide avermectin in Streptomyces avermitilis. Proc Natl Acad Sci U S A 96, 9509-9514.

Ishikawa, J. \& Hotta, K. (1999). FramePlot: a new implementation of the frame analysis for predicting protein-coding regions in bacterial DNA with a high G $+\mathrm{C}$ content. FEMS Microbiol Lett 174, 251-253.

Kamra, P., Gokhale, R. S. \& Mohanty, D. (2005). SEARCHGTr: a program for analysis of glycosyltransferases involved in glycosylation of secondary metabolites. Nucleic Acids Res 33, W220-W225.

Katz, L. (1997). Manipulation of modular polyketide synthases. Chem $\operatorname{Rev}$ 97, 2557-2576.

Kieser, T., Bibb, M. J., Buttner, M. J., Chater, K. F. \& Hopwood, D. A. (2000). Practical Streptomyces Genetics. Norwich: John Innes Foundation.

Kuhstoss, S., Huber, M., Turner, J. R., Paschal, J. W. \& Rao, R. N. (1996). Production of a novel polyketide through the construction of a hybrid polyketide synthase. Gene 183, 231-236.

Long, P. F., Wilkinson, C. J., Bisang, C. P., Cortes, J., Dunster, N., Oliynyk, M., McCormick, E., McArthur, H., Mendez, C. \& other authors (2002). Engineering specificity of starter unit selection by the erythromycin-producing polyketide synthase. Mol Microbiol 43 , $1215-1225$.

Marchler-Bauer, A. \& Bryant, S. H. (2004). CD-Search: protein domain annotations on the fly. Nucleic Acids Res 32, W327-W331.

McCabe, R. E. \& Oster, S. (1989). Current recommendations and future prospects in the treatment of toxoplasmosis. Drugs 38, 973-987.

McDaniel, R., Welch, M. \& Hutchinson, C. R. (2005). Genetic approaches to polyketide antibiotics. 1. Chem Rev 105, 543-558.

Melançon, C. E., III \& Liu, H. W. (2007). Engineered biosynthesis of macrolide derivatives bearing the non-natural deoxysugars 4-epi-Dmycaminose and 3-N-monomethylamino-3-deoxy-D-fucose. J Am Chem Soc 129, 4896-4897.

Melançon, C. E., III, Takahashi, H. \& Liu, H. W. (2004), Characterization of $t y l M 3 / t y l M 2$ and $m y d C / m y c B$ pairs required for efficient glycosyltransfer in macrolide antibiotic biosynthesis. $\mathrm{J} \mathrm{Am}$ Chem Soc 126, 16726-16727.

Melançon, C. E., III, Yu, W. L. \& Liu, H. W. (2005). TDP-mycaminose biosynthetic pathway revised and conversion of desosamine pathway to mycaminose pathway with one gene. J Am Chem Soc 127, $12240-12241$
Melançon, C. E., III, Hong, L., White, J. A., Liu, Y. N. \& Liu, H. W. (2007). Characterization of TDP-4-keto-6-deoxy-D-glucose-3,4-ketoisomerase from the D-mycaminose biosynthetic pathway of Streptomyces fradiae: in vitro activity and substrate specificity studies. Biochemistry 46, 577-590.

Merson-Davies, L. A. \& Cundliffe, E. (1994). Analysis of five tylosin biosynthetic genes from the tyllBA region of the Streptomyces fradiae genome. Mol Microbiol 13, 349-355.

Miller, V. L. \& Mekalanos, J. J. (1988). A novel suicide vector and its use in construction of insertion mutations: osmoregulation of outer membrane proteins and virulence determinants in Vibrio cholerae requires toxR. J Bacteriol 170, 2575-2583.

Nielsen, H., Engelbrecht, J., Brunak, S. \& von Heijne, G. (1997). Identification of prokaryotic and eukaryotic signal peptides and prediction of their cleavage sites. Protein Eng 10, 1-6.

Omura, S., Kitao, C., Hamada, H. \& Ikeda, H. (1979). Bioconversion and biosynthesis of 16-membered macrolide antibiotics. X. Final steps in the biosynthesis of spiramycin, using enzyme inhibitor: cerulenin. Chem Pharm Bull (Tokyo) 27, 176-182.

Omura, S., Sadakane, N., Tanaka, Y. \& Matsubara, H. (1983). Chimeramycins: new macrolide antibiotics produced by hybrid biosynthesis. J Antibiot (Tokyo) 36, 927-930.

Pang, X., Aigle, B., Girardet, J. M., Mangenot, S., Pernodet, J.-L., Decaris, B. \& Leblond, P. (2004). Functional angucycline-like antibiotic gene cluster in the terminal inverted repeats of the Streptomyces ambofaciens linear chromosome. Antimicrob Agents Chemother 48, 575-588.

Pernodet, J.-L., Alegre, M. T., Blondelet-Rouault, M.-H. \& Guérineau, M. (1993). Resistance to spiramycin in Streptomyces ambofaciens, the producer organism, involves at least two different mechanisms. J Gen Microbiol 139, 1003-1011.

Pernodet, J.-L., Fish, S., Blondelet-Rouault, M.-H. \& Cundliffe, E. (1996). The macrolide-lincosamide-streptogramin B resistance phenotypes characterized by using a specifically deleted, antibioticsensitive strain of Streptomyces lividans. Antimicrob Agents Chemother 40, 581-585.

Pernodet, J.-L., Gourmelen, A., Blondelet-Rouault, M.-H. \& Cundliffe, E. (1999). Dispensable ribosomal resistance to spiramycin conferred by srmA in the spiramycin producer Streptomyces ambofaciens. Microbiology 145, 2355-2364.

Quiros, L. M., Aguirrezabalaga, I., Olano, C., Mendez, C. \& Salas, J. A. (1998). Two glycosyltransferases and a glycosidase are involved in oleandomycin modification during its biosynthesis by Streptomyces antibioticus. Mol Microbiol 28, 1177-1185.

Rascher, A., Hu, Z., Viswanathan, N., Schirmer, A., Reid, R., Nierman, W. C., Lewis, M. \& Hutchinson, C. R. (2003). Cloning and characterization of a gene cluster for geldanamycin production in Streptomyces hygroscopicus NRRL 3602. FEMS Microbiol Lett 218, 223-230.

Raynal, A., Karray, F., Tuphile, K., Darbon-Rongère, E. \& Pernodet, J.-L. (2006). Excisable cassettes: new tools for functional analysis of Streptomyces genomes. Appl Environ Microbiol 72, 4839-4844.

Richardson, M. A., Kuhstoss, S., Solenberg, P., Schaus, N. A. \& Rao, R. N. (1987). A new shuttle cosmid vector, pKC505, for streptomycetes: its use in the cloning of three different spiramycin-resistance genes from a Streptomyces ambofaciens library. Gene 61, 231-241.

Richardson, M. A., Kuhstoss, S., Huber, M. L., Ford, L., Godfrey, O., Turner, J. R. \& Rao, R. N. (1990). Cloning of spiramycin biosynthetic genes and their use in constructing Streptomyces ambofaciens mutants defective in spiramycin biosynthesis. J Bacteriol 172, 3790-3798.

Salzberg, S. L., Delcher, A. L., Kasif, S. \& White, O. (1998). Microbial gene identification using interpolated Markov models. Nucleic Acids Res 26, 544-548. 
Sambrook, J. \& Russell, D. W. (2001). Molecular Cloning: a Laboratory Manual, 3rd edn. Cold Spring Harbor, NY: Cold Spring Harbor Laboratory.

Schoner, B., Geistlich, M., Rosteck, P., Jr, Rao, R. N., Seno, E., Reynolds, P., Cox, K., Burgett, S. \& Hershberger, C. (1992). Sequence similarity between macrolide-resistance determinants and ATPbinding transport proteins. Gene 115, 93-96.

Schönfeld, W. \& Kirst, H. A. (editors) (2002). Macrolide Antibiotics. Basel: Birkhaüser Verlag.

Simon, R., Priefer, U. \& Pühler, A. (1983). A broad host range mobilization system for in vivo genetic engineering: transposon mutagenesis in gram negative bacteria. Biotechnology (N Y) 1, 784-791.

Smith, C. R. (1988). The spiramycin paradox. J Antimicrob Chemother 22 (Suppl. B), 141-144.

Stratigopoulos, G., Bate, N. \& Cundliffe, E. (2004). Positive control of tylosin biosynthesis: pivotal role of TylR. Mol Microbiol 54, 1326-1334.

Summers, R. G., Donadio, S., Staver, M. J., Wendt-Pienkowski, E., Hutchinson, C. R. \& Katz, L. (1997). Sequencing and mutagenesis of genes from the erythromycin biosynthetic gene cluster of Saccharopolyspora erythraea that are involved in L-mycarose and Ddesosamine production. Microbiology 143, 3251-3262.
Takahashi, H., Liu, Y.-N., Chen, H. \& Liu, H.-W. (2005). Biosynthesis of TDP-L-mycarose: the specificity of a single enzyme governs the outcome of the pathway. J Am Chem Soc 127, 9340-9341.

Waldron, C., Matsushima, P., Rosteck, P. R., Jr, Broughton, M. C., Turner, J., Madduri, K., Crawford, K. P., Merlo, D. J. \& Baltz, R. H. (2001). Cloning and analysis of the spinosad biosynthetic gene cluster of Saccharopolyspora spinosa. Chem Biol 8, 487-499.

Wu, K., Chung, L., Revill, W. P., Katz, L. \& Reeves, C. D. (2000). The FK520 gene cluster of Streptomyces hygroscopicus var. ascomyceticus (ATCC 14891) contains genes for biosynthesis of unusual polyketide extender units. Gene 251, 81-90.

Yu, D., Ellis, H. M., Lee, E. C., Jenkins, N. A., Copeland, N. G. \& Court, D. L. (2000). An efficient recombination system for chromosome engineering in Escherichia coli. Proc Natl Acad Sci U S A 97, 59785983.

Zhao, Z., Hong, L. \& Liu, H. W. (2005). Characterization of protein encoded by $s p n R$ from the spinosyn gene cluster of Saccharopolyspora spinosa: mechanistic implications for forosamine biosynthesis. J Am Chem Soc 127, 7692-7693.

Edited by: P. R. Herron 